\title{
KESIAPSIAGAAN BENCANA BANJIR MASYARAKAT DUSUN KESONGO
}

\section{Dyah Rahmawatie Ratna Budi Utami*, Dewi Kartika Sari, Riyani Wulandari, Anjula Roselini Istiqomah}

\author{
Sarjana Keperawatan/Fakultas Ilmu Kesehatan, Universitas 'Aisyiyah Surakarta \\ *Email:dyahrahmawatie@gmail.com
}

\begin{tabular}{|c|c|}
\hline & Abstract \\
\hline $\begin{array}{l}\text { Kesiapsiagaan; } \\
\text { bencana; banjir }\end{array}$ & $\begin{array}{l}\text { Latar Belakang: Bencana banjir sering terjadi pada mayarakat yang } \\
\text { tinggal di pinggiran sungai, sehingga masyarakat perlu memahami } \\
\text { kesiapsiagaan bencana untuk mengantisipasi dan merespon jika terjadi } \\
\text { bencana banjir. Kesiapsiagaan dalam menghadapi bencana banjir } \\
\text { meliputi tingginya kemampuan mengenali bencana yang berpotensi } \\
\text { terjadi di lingkungan tempat tinggal, kemampuan mengenali tanda-tanda } \\
\text { akan terjadinya bencana dan kesadaran untuk mengelola lingkungan } \\
\text { tempat tinggal yang ramah bencana. Pemahaman tentang kesiapsiagaan } \\
\text { dapat mengurangi dampak yang ditimbulkan akibat bencana banjir. } \\
\text { Tujuan: Mengetahui kesiapsiagaan masyarakat pinggiran sungai dalam } \\
\text { menghadapi bencana banjir di Dusun Kesongo, Desa Tegalmade, } \\
\text { Kecamatan Mojolaban, Kabupaten Sukoharjo. Metode: Penelitian } \\
\text { descriptive survey, teknik pengambilan sampel purposive sampling, } \\
\text { populasi } 210 \text { kepala keluarga, sampel } 138 \text { responden, instrumen } \\
\text { penelitian kuesioner. Analisa data univariat. Hasil: Hasil penelitian } \\
\text { menunjukkan mayoritas warga berumur > } 40 \text { tahun sebanyak } 96 \\
\text { responden (69.6\%), berpendidikan SD/MI sebanyak } 59 \text { responden } \\
\text { (42.8\%), pekerjaan petani sebanyak } 72 \text { responden (52.2\%), warga } \\
\text { mempunyai pengetahuan baik sebanyak } 70 \text { responden (50.7\%), } \\
\text { mempunyai rencana tanggap darurat siap sebanyak } 138 \text { responden } \\
\text { (100\%), mempunyai sistem peringatan dini yang tepat sebanyak 138 } \\
\text { responden (100\%) dan mempunyai kesiapsiagaan tinggi sebanyak } 89 \\
\text { responden (64.5\%). Kesimpulan: Mayoritas warga di Dusun Kesongo } \\
\text { mempunyai kesiapsiagaan tinggi yaitu sebanyak } 89 \text { responden (64.5\%) }\end{array}$ \\
\hline
\end{tabular}

\section{PENDAHULUAN}

Badan Nasional Penanggulangan Bencana (BNPB) menyebutkan terdapat 1.244 kejadian bencana alam di Indonesia sepanjang tahun 2009-2018 dengan kejadian tertinggi adalah tanah longsor dan disusul banjir. Prevalensi kejadian banjir menempati ranking ke 3 di Jawa Tengah. Bencana banjir menempati posisi kedua kejadian bencana yang sering terjadi di Kabupaten Sukoharjo (BNBP, 2018).

Beberapa desa di Kabupaten Sukoharjo selama ini sudah menjadi langganan banjir karena lokasinya yang berada di sepanjang bantaran sungai Bengawan Solo. Beberapa desa yang rawan banjir tersebut tersebar di Kecamatan Sukoharjo, Nguter, Gatak, 
Grogol, Weru, Tawangsari, Polokarto dan Mojolaban (Puryono, 2016).

Dusun Kesongo, Desa Tegalmade, Kecamatan Mojolaban adalah wilayah di Kabupaten Sukoharjo yang rawan terjadinya banjir karena dusun ini dekat dengan sungai Bengawan Solo dan sungai Samin. Banjir terparah terjadi pada tahun 2007 karena tanggul sungai Samin jebol sehingga air sungai langsung merendam ribuan rumah penduduk. Ketinggian banjir mencapai lebih dari dua meter (Wicaksono, 2018)

Banjir merupakan peristiwa atau kejadian yang mengakibatkan terendamnya suatu daerah atau daratan karena volume air yang meningkat. Banjir disebabkan oleh perubahan iklim, kurangnya resapan air di daerah hulu karena banyaknya bangunan/rumah pemukiman yang di pinggiran sungai dan rendahnya kesadaran masyarakat untuk menjaga kebersihan sungai (Rijanta, 2014)

Masyarakat pinggiran sungai beresiko mengalami banjir, oleh karena itu diperlukan pemahaman mengenai kesiapsiagaan bencana banjir untuk menghadapi dan mengantisipasi banjir. Kesiapsiagaan adalah serangkaian kegiatan yang dilakukan untuk mengantisipasi bencana melalui pengorganisasian berbagai sumber daya serta melalui langkah yang tepat guna dan berdaya guna (Fitriadi, 2017). Terdapat 3 indikator kesiapsiagaan bencana yaitu : pengetahuan/Knowledge $(\mathrm{K})$, perencanaan kedaruratan/ Emergency Planning (EP) dan sistem peringatan dini/ Warning System (WS) (Susanto, 2016).

Pemahaman tentang kesiapsiagaan bencana perlu dimengerti oleh seluruh kalangan masyarakat guna mengurangi berbagai dampak baik materi maupun non materi yang ditimbulkan akibat bencana banjir. Adapun tujuan dari penelitian ini adalah untuk mengidentifikasi gambaran kesiapsiagaan masyarakat pinggiran sungai dalam menghadapi bencana banjir di Dusun Kesongo, Desa Tegalmade,
Kecamatan Mojolaban, Kabupaten Sukoharjo.

\section{METODE PENELITIAN}

Penelitian ini merupakan penelitian kuantitatif dengan rancangan deskriptif. Penyebaran kuesioner dilakukan satu kali kepada 138 responden yakni warga yang tinggal di dusun Kesongo Desa Tegalmande yang memenuhi kriteria inklusi : a) Warga yang bersedia menjadi responden, b)Warga yang sudah pernah mengalami kejadian banjir, c)Warga yang berusia $>17$ tahun. Adapun kriteria eksklusi adalah warga yang tidak berada di tempat saat dilakukan pengambilan data.

Instrumen yang digunakan sebagai alat pengambilan data merupakan hasil modifikasi penelitian Purwoko (2015) yang terdiri dari 3 sub variabel yakni pengetahuan, rencana tanggap darurat dan sistem deteksi dini. Pernyataan pengetahuan ini disusun menggunakan dua alternatif yaitu "Benar" dan "Salah" atau "Ya" dan "Tidak". Sedangkan skala likert digunakan untuk mengukur rencana tanggap darurat dan sistem peringatan dini dengan menggunakan skor dengan rentang skala likert 1-5

Uji validitas dan reliabilitas dilakukan pada 30 responden di Desa Laban, Kecamatan Mojolaban, dan hasilnya 30 item pertanyaan dan pernyataan dikatakan valid dan reliabel. Desa Laban dipilih menjadi lokasi uji validitas karena merupakan wilayah dengan kejadian banjir kedua setelah Dusun Kesongo, Desa Tegalmade. Analisa data yang digunakan dalam penelitian ini adalah metode analisa univariat yang dilakukan pada variabel kesiapsiagaan yang terdiri dari sub variabel pengetahuan, rencana tanggap darurat dan sistem peringatan dini) dalam bentuk distribusi frekuensi.

\section{HASIL PENELITIAN}

Penelitian ini mengidentifikasi gambaran kesiapsiagaan masyarakat pinggiran sungai dalam menghadapi 
bencana banjir di Dusun Kesongo Desa Tegalmade Kecamatan Mojolaban Kabupaten Sukoharjo.

\section{Karakteristik Responden}

Tabel 1. Distribusi Frekuensi karaktristik Responden

\begin{tabular}{|c|c|c|c|}
\hline No & Umur & $\mathrm{F}$ & $(\%)$ \\
\hline 1 & 21-29 tahun & 5 & 3.6 \\
\hline 2 & 30-40 tahun & 37 & 26.8 \\
\hline \multirow[t]{2}{*}{3} & $>40$ tahun & 96 & 69.6 \\
\hline & Jumlah & 138 & 100 \\
\hline No & Pendidikan & $\mathrm{F}$ & $(\%)$ \\
\hline 1 & SD/MI & 59 & 42.8 \\
\hline 2 & SMP/MTS & 47 & 34.1 \\
\hline 3 & SMA/MA & 32 & 23.2 \\
\hline \multirow[t]{2}{*}{4} & Akademi/Universitas & 0 & 0 \\
\hline & Jumlah & 138 & 100 \\
\hline No & Pekerjaan & $\mathrm{F}$ & $(\%)$ \\
\hline 1 & Guru & 0 & 0 \\
\hline 2 & IRT & 0 & 0 \\
\hline 3 & Wiraswasta & 7 & 5.1 \\
\hline 4 & Petani & 72 & 52.2 \\
\hline 5 & Swasta & 28 & 20.3 \\
\hline \multirow[t]{2}{*}{6} & Lain-lain & 31 & 22.5 \\
\hline & Jumlah & 138 & 100 \\
\hline
\end{tabular}

Berdasarkan tabel 1 didapatkan hasil bahwa mayoritas usia responden adalah lebih dari 40 tahun, pendidikan SD/MI dan pekerjaan adalah petani.

Pengetahuan

Tabel 2 Distribusi Frekuensi Responden

\begin{tabular}{clcc}
\hline No & Pengetahuan & F & $(\%)$ \\
\hline 1 & Baik & 70 & 50.7 \\
2 & Cukup & 65 & 47.1 \\
3 & Kurang & 3 & 2.2 \\
\hline & Jumlah & 138 & 100 \\
\hline
\end{tabular}

Sumber: data primer diolah tahun 2019

Berdasarkan Tingkat Pengetahuan tentang Kesiapsiagaan dalam Menghadapi Bencana Banjir mayoritas pengetahuan warga di Dusun Kesongo Desa Tegalmade Kecamatan Mojolaban Kabupaten Sukoharjo diketahui bahwa mayoritas responden memiliki pengetahuan baik yaitu sebanyak 70 responden $(50.7 \%$ ).

\section{Rencana Tanggap Darurat}

Tabel 3 Distribusi Frekuensi Responden Berdasarkan Rencana Tanggap Darurat Tentang Kesiapsiagaan dalam Menghadapi Bencana Banjir

\begin{tabular}{clcc}
\hline No & $\begin{array}{c}\text { Rencana tanggap } \\
\text { darurat }\end{array}$ & $\mathrm{F}$ & $(\%)$ \\
\hline 1 & Siap & 138 & 100 \\
2 & Kurang siap & 0 & 0 \\
\hline & Jumlah & 138 & 100 \\
\hline
\end{tabular}

Sumber: data primer diolah tahun 2019

\section{Sistem Peringatan Dini}

Tabel 4 Distribusi Frekuensi Sistem Peringatan Dini Tentang Kesiapsiagaan dalam Menghadapi Bencana Banjir

\begin{tabular}{|c|c|c|c|}
\hline No & $\begin{array}{c}\text { Sistem } \\
\text { peringatan dini }\end{array}$ & $\mathrm{F}$ & $(\%)$ \\
\hline 1 & Tepat & 138 & 100 \\
\hline \multirow[t]{2}{*}{2} & Kurang tepat & 0 & 0 \\
\hline & Jumlah & 138 & 100 \\
\hline \multicolumn{4}{|c|}{ Sumber: data primer diolah tahun 2019} \\
\hline \multicolumn{4}{|c|}{ Sistem peringatan dir } \\
\hline \multicolumn{4}{|c|}{ Dusun Kesongo Desa } \\
\hline \multicolumn{4}{|c|}{ Kecamatan Mojolaban } \\
\hline \multicolumn{4}{|c|}{$\begin{array}{l}\text { Sukoharjo diketahui bahwa mayoritas } \\
\text { responden mempunyai sistem peringatan }\end{array}$} \\
\hline \multicolumn{4}{|c|}{$\begin{array}{l}\text { dini yang tepat yaitu sebanyak } 138 \\
\text { responden }(100 \%) \text {. }\end{array}$} \\
\hline
\end{tabular}

\section{Kesiapsiagaan}

Tabel 5 Distribusi Frekuensi Responden Berdasarkan Kesiapsiagaan Warga dalam Menghadapi Bencana Banjir di Dusun Kesongo Desa Tegalmade Kecamatan Mojolaban Kabupaten Sukoharjo

\begin{tabular}{clcc}
\hline No & Kesiapsiagaan & F & $(\%)$ \\
\hline 1 & Sangat tinggi & 37 & 26.8 \\
2 & Tinggi & 89 & 64.5 \\
3 & Rendah & 12 & 8.7 \\
4 & Sangat rendah & 0 & 0 \\
\hline & Jumlah & 138 & 100 \\
\hline
\end{tabular}

Sumber: data primer diolah tahun 2019

\section{PEMBAHASAN}

Mayoritas responden berusia lebih dari 40 tahun. Semakin tua umur seseorang maka semakin banyak pengalaman yang dimiliki seseorang (Setyaningrum, 2018) 
Mayoritas responden memiliki pendidikan adalah SD/MI. Hal ini sejalan dengan penelitian yang menjelaskan bahwa tingkat pendidikan kepala keluarga di Desa Balerante Kecamatan Kemalang mayoritas adalah pendidikan dasar (76.5\%). Ketidakmampuan masyarakat menjangkau fasilitas pendidikan menengah akibat jarak yang jauh menjadi penyebab rendahnya tingkat pendidikan kepala keluarga (Nurhidayah, 2018)

Rendahnya tingkat pendidikan masyarakat diakibatkan adanya keterbatasan biaya, sarana dan prasarana. Hal ini terlihat dari minimnya sarana pendidikan, jumlah sekolah dan guru yang terbatas. Jarak yang jauh juga menjadi penghambat bagi masyarakat untuk bersekolah. Biaya yang tinggi dan kemampuan ekonomi masyarakat yang rendah merupakan penyebab utama masyarakat tidak melanjutkan pendidikan ke jenjang sekolah menengah atau perguruan tinggi. Selain itu juga belum diterapkannya wajib belajar 9 tahun pada zaman itu sehingga saat ada keterbatasan biaya maka masyarakat tidak bisa mengakses pendidikan.

Berdasarkan tabel 1 distribusi pekerjaan warga di Dusun Kesongo Desa Tegalmade Kecamatan Mojolaban Kabupaten Sukoharjo diketahui bahwa mayoritas responden sebagai petani sebanyak 72 responden $(52.2 \%)$. Hal tersebut menjadikan warga memilih sebagai petani daripada karyawan swasta, tingkat pendidikan yang rendah juga menjadi alasan masyarakat tidak punya pilihan pekerjaan lain kecuali bekerja sebagai petani (Putri, 2016). Masyarakat Dusun Kesongo memenuhi kebutuhannya memilih sebagai petani karena tempat tinggal mereka banyak sawah yang subur dan hasil panen yang melimpah.

Pengetahuan

Pengetahuan merupakan hasil dari tahu yang didapatkan seseorang melalui penginderaan terhadap suatu kejadian. Disini masyarakat sebagai pelaku awal penanggulangan bencana dapat melihat, mengamati, mendengar dan merasakan secara langsung terjadinya bencana dilingkungannya. Tingkat pengetahuan masyarakat yang tinggal di daerah rawan bencana akan lebih baik dibandingkan dengan tingkat pengetahuan masyarakat yang tinggal di daerah kurang rawan bencana (Juhadi, 2016). Mayoritas warga Dusun Kesongo mempunyai pengetahuan baik, pengetahuan yang baik diperoleh dari pengalaman banjir yang sering dialami karena mereka tinggal di daerah yang rawan terjadi banjir. Pengetahuan yang baik salah satunya diperoleh dari adanya kegiatan simulasi atau informasi bencana dari BPBD maupun dari SAR (Search And Rescue).

Hal ini sesuai dengan hasil wawancara kepada warga Dusun Kesongo bahwa pengetahuan yang baik didapatkan dari pengalaman akan kejadian bencana banjir yang pernah dialami warga rata-rata sebanyak 20-30 kali sampai tahun 2019 ini. Pengetahuan yang baik juga diperoleh dari adanya kegiatan simulasi atau informasi bencana dari BPBD maupun dari SAR.

Rencana untuk keadaan darurat bencana ini menjadi bagian yang penting dalam kesiapsiagaan terutama berkaitan dengan evakuasi, pertolongan pertama dan penyelamatan korban bencana dapat diminimalkan. Upaya ini sangat penting terutama pada saat terjadinya bencana dan hari-hari pertama setelah bencana sebelum datangnya bantuan dari pihak luar (Murbawan, 2017) . Untuk Dusun Kesongo sendiri, rencana tanggap darurat yang dilakukan yaitu membuat rencana evakuasi dengan membuat perahu dengan jerigen air berukuran 30 liter yang dirangkai menggunakan besi dan menyiapkan keperluan apabila terjadi kondisi darurat seperti obat-obatan, makanan dan minuman.

Siapnya individu/rumah tangga berdasarkan rencana tanggap darurat disebabkan karena individu/rumah tangga secara umum mengetahui apa yang harus dilakukan untuk menyelamatkan diri dari 
banjir seperti menambah pengetahuan tentang banjir, koordinasi yang terjalin dengan baik antara warga dengan para petugas BPBD, adanya kesepakatan tempat pengungsian atau evakuasi, mengetahui tempat menyelamatkan diri pada saat banjir terjadi dan tersedianya kotak obat oleh kader kesehatan maupun di pengungsian. Tinggi rendahnya nilai indeks rencana tanggap darurat juga dipengaruhi oleh pengalaman masyarakat (Murbawan, 2017).

Sistem peringatan dini merupakan bagian penting dari kesiapsiagaan dalam menghadapi bencana. Tanda yang diberikan dari sistem peringatan akan disampaikan baik langsung maupun tidak langsung, kemudian masyarakat dapat merespon peringatan tersebut. Sistem peringatan yang efektif sangat bermanfaat untuk menghindarkan diri dari bahaya yang mungkin terjadi (Farizi, 2016)

Sistem peringatan dini yang digunakan di Dusun Kesongo masih sederhana yaitu dengan menggunakan suara kentongan yang dipukul sebanyak 4 kali. Suara kentongan digunakan supaya masyarakat tetap melestarikan sistem kearifan lokal yang ada. Kentongan diletakkan di pos ronda dan dipukul oleh pemangku adat apabila banjir datang.

Sistem peringatan bencana yang digunakan oleh masyarakat dalam melakukan peringatan bencana masih sangat sederhana yaitu dengan cara tradisional. Cara tradisional disini adalah berupa peringatan menggunakan kentongan, pengumuman dengan toa, peringatan dengan mengetuk rumah demi rumah, pengumuman dari tempat ibadah, informasi dari pemerintah dan informasi dari TV (Susanto, 2016)

Berdasarkan tabel 5 dapat diketahui bahwa mayoritas responden memiliki kesiapsiagaan tinggi yaitu sebanyak 89 responden $(64.5 \%)$. Tingkat kesiapsiagaan masyarakat di Desa Jaro Kecamatan Jaro Kabupaten Tabalong dapat dikategorikan tinggi dalam menghadapi bencana tanah longsor. Kesiapsiagaan warga menghadapi bencana alam tanah longsor meliputi tingginya kemampuan mengenali bencana yang berpotensi terjadi di lingkungan tempat tinggal, kemampuan mengenali tanda-tanda akan terjadinya bencana seperti hujan terus menerus bisa menyebabkan banjir dan kesadaran untuk mengelola lingkungan tempat tinggal yang rawan bencana. Kesiapsiagaan masyarakat dalam menghadapi tanah longsor akan menimbulkan dampak positif yaitu dapat mencegah kerusakan rumah, lahan perkebunan, jalan dan mengurangi korban jiwa (Fitriadi, 2017).

Berbagai upaya kesiapsiagaan yang dilakukan masyarakat dalam menghadapi bencana banjir berbeda-beda sesuai dengan pengalaman yang dirasakan selama kejadian banjir. Upaya kesiapsiagaan masyarakat Desa Bintaro meliputi: membersihkan lingkungan dan membuang sampah pada tempatnya, evakuasi diri, menaikkan barang-barang dan membersihkan lantai dan perabotan rumah (Nurrahmah, 2017)). Sedangkan upaya kesiapsiagaan yang dilakukan masyarakat Dusun Kesongo yaitu seperti mencari informasi, membuat rencana evakuasi dengan membuat perahu dengan jerigen air berukuran 30 liter yang dirangkai menggunakan besi dan menyiapkan keperluan apabila terjadi kondisi darurat seperti obat-obatan, makanan dan minuman.

Dusun Kesongo memiliki kesiapsiagaan tinggi. Hal ini sesuai dengan hasil wawancara kepada warga Dusun Kesongo bahwa upaya kesiapsiagaan yang dilakukan yaitu dengan mencari informasi tentang bencana, membuat rencana evakuasi menyiapkan keperluan apabila terjadi kondisi darurat seperti obat-obatan, makanan dan minuman. Upaya kesiapsiagaan yang tinggi dapat menimbulkan dampak positif yaitu dapat mencegah kerusakan rumah, lahan perkebunan, jalan dan mengurangi korban jiwa. 


\section{SIMPULAN DAN SARAN}

Pengetahuan warga mengenai kesiapsiagaan dalam menghadapi bencana banjir di Dusun Kesongo adalah baik, rencana tanggap darurat siap, sistem peringatan dini yang tepat dan mayoritas memiliki kesiapsiagaan tinggi. Untuk mengoptimalkan peran warga dalam kesiapsiagaan menghadapi banjir perlu untuk senantiasa berkoordinasi dalam bidang terkait serta pemantapan sistem komunikasi yang sudah terbentuk.

\section{DAFTAR PUSTAKA}

Badan Nasional Penanggulangan Bencana. (2018). Data Informasi Bencana Indonesia. Badan Nasional Penanggulangan Bencana, $<$ http:/www.bnpb.cloud/dibi/laporan 4/>. Diakses tanggal 5 November 2018.

Farizi, I., Ismail, N., dan Aulia, B. (2016). Analisis Kesiapsiagaan UPDT Pusat Penanggulangan Krisis Kesehatan (P2KK) Dinas Kesehatan Aceh dalam Menghadapi Bencana Gempa Bumi. Jurnal Ilmu Kebencanaan 3(2):85-93.

Fitriadi, M., Kumalawati, R., dan Arisanty, D. (2017). Tingkat Kesiapsiagaan Masyarakat Terhadap Bencana Tanah Longsor di Desa Jaro Kecamatan Jaro Kabupaten Tabalong. Jurnal Pendidikan Geografi 4(4): 32-41.

Juhadi., Setyaningsih, W., dan Kurniasari, N. (2016). Pola Perilaku Masyarakat dalam Pengurangan Resiko Bencana Tanah Longsor di Kecamatan Banjarwangu Kabupaten Banjarnegara Jawa Tengah. Jurnal Geografi 13(2):1-9.

Murbawan, I., Ma'ruf, A., dan Manan, A. (2017). Kesiapsiagaan Rumah Tangga dalam Mengantisipasi Bencana Banjir di Daerah Aliran Sungai (DAS) Wangu. Ecogreen 3(2):59-69.
Nurhidayati, I., dan Ratnawati, E. (2018). Kesiapsiagaan Keluarga dengan Lanjut Usia pada Kejadian Letusan Gunung Merapi di Desa Belerante Kecamatan Kemalang. Jurnal Keperawatan dan Kesehatan Masyarakat 7(1):20-31.

Nurrahmah, W. (2015). Pengalaman Kesiapsiagaan Masyarakat Menghadapi Bencana Banjir di RT 001 RW 012 Kelurahan Bintaro Kecamatan Pesanggrahan Jakarta Selatan Tahun 2015. Skripsi. Universitas Islam Negeri Syarif Hidayatullah. Jakarta.

Putri, A. D., dan Setiawina, N. D. (2016). Pengaruh Umur, Pendidikan, Pekerjaan terhadap Pendapatan Rumah Tangga Miskin di Desa Bebandem. E-jurnal EP Unud 2(4):173-180.

Purwoko, A. (2015). Pengaruh Pengetahuan dan Sikap tentang Resiko Bencana Banjir terhadap Kesiapsiagaan Remaja Usia 15-18 Tahun dalam Menghadapi Bencana Banjir di Kelurahan Pedurungan Kidul Kota Semarang. Skripsi. Universitas Negeri Semarang. Semarang.

Puryono, E. (2016). BPBD Sukoharjo: 70 Desa/Kelurahan Rawan Banjir Dan Tanah Longsor. RRI Surakarta.7 Januari.<http:/www.m.radio.co.id/post /berita/235123/bpbd_sukoharjo_70_de sa/kelurahan_rawan_banjir_dan_tanah _longsor.com/>. Diakses 5 November 2018.

Rijanta, R., Hizbaron, D. R., dan Baiquni, M. (2014). Modal Sosial dalam Manajemen Bencana. Cetakan Pertama. Gadjah Mada University Press. Yogyakarta. 
Setyaningrum, N., dan Rumagutawan, R. 2018. 2018. Tingkat Pengetahuan Penanggulangan Bencana dan Kesiapsiagaan Bencana Gempa Bumi pada Kepala Keluarga di Dusun Kiringan Canden Jetis Bantul Yogyakarta. Health Sciences and Pharmacy Journal 2(3):103-110.

Susanto, N., dan Putranto, T. T. (2016). Analisis Level Kesiapsiagaan Warga Menghadapi Potensi Bencana Longsor Kota Semarang. Jurnal Teknik 37(2): 54-58.
Wicaksono, E. (2018). Banjir Sukoharjo: Air Kali Samin Meluap Rendam Jalan Perkampungan Tegalmade. Surat Kabar Solopos. 8 Februari. <http://www.jatengpos.com/2018/02/b anjir-sukoharjo-air-kali-saminmeluap-rendam-jalan-perkampungantegalmade.com>. Diakses 5 November 2018. 